\title{
The intrinsic plasticity of farm businesses and their resilience to change. An Australian example
}

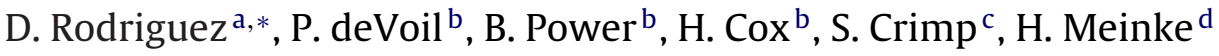 \\ a Queensland Alliance for Agriculture and Food Innovation (QAAFI), University of Queensland, and Agricultural Production Systems Research (APSRU), \\ PO Box 102, Toowoomba Qld (4350), Australia \\ ${ }^{\mathrm{b}}$ Agri-Science Queensland, and Agricultural Production Systems Research (APSRU), PO Box 102, Toowoomba Qld (4350), Australia

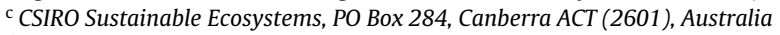 \\ d Tasmanian Institute of Agricultural Research (TIAR), University of Tasmania, Australia PB 98, Hobart TAS 7001, Australia
}

\section{A R T I C L E I N F O}

\section{Article history:}

Received 13 January 2011

Received in revised form 28 February 2011

Accepted 28 February 2011

\section{Keywords:}

Decision making

Climate change

Adaptation

Whole farm modelling

\begin{abstract}
A B S T R A C T
This paper examines the idea that plasticity in farm management introduces resilience to change and allows farm businesses to perform when operating in highly variable environments. We also argue for the need to develop and apply more integrative assessments of farm performance that combine the use of modelling tools with deliberative processes involving farmers and researchers in a co-learning process, to more effectively identify and implement more productive and resilient farm businesses.

In a plastic farming system, farm management is highly contingent on environmental conditions. In plastic farming systems farm managers constantly vary crops and inputs based on the availability of limited and variable resources (e.g. land, water, finances, labour, machinery, etc.), and signals from its operating environment (e.g. climate, markets), with the objective of maximising a number of, often competing, objectives (e.g. maximise profits, minimise risks, etc.). In contrast in more rigid farming systems farm management is more calendar driven and relatively fixed sequences of crops are regularly followed over time and across the farm. Here we describe the application of a whole farm simulation model to (i) compare, in silico, the sensitivity of two farming systems designs of contrasting levels of plasticity, operating in two contrasting environments, when exposed to a stressor in the form of climate change scenarios;(ii) investigate the presence of interactions and feedbacks at the field and farm levels capable of modifying the intensity and direction of the responses to climate signals; and (iii) discuss the need for the development and application of more integrative assessments in the analysis of impacts and adaptation options to climate change.

In both environments, the more plastic farm management strategy had higher median profits and was less risky for the baseline and less intensive climate change scenarios (2030). However, for the more severe climate change scenarios (2070), the benefit of plastic strategies tended to disappear. These results suggest that, to a point, farming systems having higher levels of plasticity would enable farmers to more effectively respond to climate shifts, thus ensuring the economic viability of the farm business. Though, as the intensity of the stress increases (e.g. 2070 climate change scenario) more significant changes in the farming system might be required to adapt. We also found that in the case studies analysed here, most of the impacts from the climate change scenarios on farm profit and economic risk originated from important reductions in cropping intensity and changes in crop mix rather than from changes in the yields of individual crops. Changes in cropping intensity and crop mix were explained by the combination of reductions in the number of sowing opportunities around critical times in the cropping calendar, and to operational constraints at the whole farm level i.e. limited work capacity in an environment having fewer and more concentrated sowing opportunities. This indicates that indirect impacts from shifts in climate on farm operations can be more important than direct impacts from climate on the yield of individual crops. The results suggest that due to the complexity of farm businesses, impact assessments and opportunities for adaptation to climate change might also need to be pursued at higher integration levels than the crop or the field. We conclude that plasticity can be a desirable characteristic in farming systems operating in highly variable environments, and that integrated whole farm systems analyses of impacts and adaptation to climate change are required to identify important interactions between farm management decision rules, availability of resources, and farmer's preference.
\end{abstract}

Crown Copyright (C) 2011 Published by Elsevier B.V. All rights reserved.

\footnotetext{
* Corresponding author. Tel.: +61 74688 1437; fax: +61 746681193.

E-mail address: d.rodriguez@uq.edu.au (D. Rodriguez).
} 


\section{Introduction}

The rate of on-going climate change (Rahmsdorf et al., 2007), its attributed impacts (Rosenzweig et al., 2008), and the likely event that insufficient mitigation action will lead to more than $2{ }^{\circ} \mathrm{C}$ of global warming are making the need for planned adaptation 'enormous' (Parry et al., 2009).

While the case for planned adaptation is overwhelming, identifying, evaluating and effectively initiating planned adaptation actions remain challenging. This is largely a function of the uncertainty surrounding the trajectory of climate change, and the outcomes of on-going autonomous adaptations. While these uncertainties exist, addressing questions like - adapting to what?, by what extent?, and by when?, will remain challenging research issues.

The purpose of undertaking planned agricultural adaptation is to effectively prepare and position practitioners to manage climate risks, improve profits and resource sustainability over the coming decades as climates change (Howden et al., 2007). In the case of cropping systems, changes in practices at the crop level, i.e. via extension of existing climate risk management strategies that mitigate present climate variability, will still be a key component in adapting to climate change (IPCC, 2007). Farmers continuously adapt their management practices in response to perceived changes in their operational environment (i.e. incremental adaptation). However, for farmers to successfully react/adapt to change, relevant experiential information needs to be available (Schwartz and Sharpe, 2006), so that feasible options can be evaluated and their likely technological, social, economic or managerial impacts understood. An interesting problem therefore arises in the absence of relevant experience, as when decision makers face unprecedented changes. This is the particular case of farming having to prepare for climate change and its uncertainties. In the case of adapting to climate change, little or no experience might be available to farmers to relate to, leaving them with limited ability to choose the best possible actions. Therefore, in face of unprecedented change, medium and long term farm business planning will require far greater levels of support to ensure success. Additionally, many farmers find long-term projections of climatic changes irrelevant while under pressure to resolve more immediate day-today and season-to-season decisions. While attitudinally, accepting that present climatic trends are likely to continue in the future, and that existing projected climate changes are realistic and useful, will require time to be processed and incorporated in farmers' planning processes (Howden et al., 2007).

Under uncertainty the concept of resilience can help to identify feasible pathways to introduce adaptedness in a system while maintaining the necessary flexibility to respond to change and emerging opportunities (Nelson et al., 2007). Here we define resilience as the ability of a farm business to absorb disturbances while remaining productive and profitable, e.g. "the capacity for self-organisation, and the capacity to adapt to stress and change" (IPCC, 2007). In addition, the concept of Adaptive resilience adds flexibility in the face of an uncertain future to the usual understanding of resilience (Mickey Glantz, 2011, pers. com, http://www.fragilecologies.com/apr28_08.html). Resilience is also linked to the concepts of vulnerability and adaptive capacity. According to Gallopin (2006), both resilience and adaptive capacity are measures of the capacity of a system to respond and reduce vulnerability when exposed to an external stress. Here we propose that an important characteristic of resilient systems is their level of plasticity, i.e. the capacity of the system to opportunistically respond to variability; for the case of farm businesses this relates to their flexibility in tactical management and strategic planning. We define plasticity in farm management as the outcome from flexible and opportunistic management rules that moderate potential impacts, or benefit from the opportunities associated with operating in a highly variable environment. Plastic farm businesses have higher ability to respond, and profit from variability, by consciously or automatically adjusting options to reliable clues from the environment in which they operate (natural, human).

In agriculture, examples of more environmentally contingent farming systems can be found in the USA's Great Plains "dynamic" cropping systems (Tanaka et al., 2002; Hansen et al., 2007); in Australia's “opportunistic cropping systems" (Hammer et al., 2001; Armstrong et al., 2003; Sadras et al., 2003; Chataway et al. 2003); and in Africa's "response farming" (Stewart and Faught, 1984; Stewart and Kashasha, 1984; Wafula, 1995). In the Great Plains of North America dynamic cropping systems were proposed as a way to increase the sustainability of cropping systems. In Australia, opportunistic cropping emerged as a strategy to cope with the risks and opportunities from well-defined patterns of inter-annual climate variability i.e. El Niño and the Southern Oscillation Index (Stone et al., 1996). In Africa, "response farming" was proposed as an environmental contingent approach to boosting crop yields and shedding poverty during good rainfall seasons, while providing food security during low rainfall seasons (http://responsefarming.org/). Apart from differences in terminology and methodologies, all three examples suggest the need for the development of more plastic production systems better able to cope with highly variable production environments such as climate and markets. Despite the general acceptance that plasticity might be good for adaptation in variable environments, so far there has been no attempt to identify how plasticity could be achieved, what are the trade-offs between plastic and not plastic farming systems, and how plasticity might translate into increased resilience, adaptedness and reduced vulnerability.

Here we postulate that as in evolutionary ecology (DeWitt and Schneider, 2004), plasticity in farming systems is a systems characteristic that increases the resilience of farm businesses; and test the hypothesis that farming systems that exhibit contrasting levels of plasticity in their tactical and strategic management will achieve different levels of resilience when exposed to a stressor such as a climate change.

\section{Methods}

To test the hypothesis above we used an extended (whole farm) configuration of the cropping systems model APSIM (Keating et al., 2003) to study the sensitivity of a number of bio-economic parameters of four farm businesses having contrasting levels of "intrinsic plasticity", when exposed to a range of climate change scenarios. The four farm designs were described in collaboration with farmers, consultants and expert agronomists. Here, climate change scenarios were used with the only aim of introducing stress i.e. hardship in the operating environment of the farm businesses, and not with the intention of predicting their future economic performance. By studying the impacts of the disturbance on bio-physical and economic performance indicators of the farm businesses we expected to gain insights into whole farm sensitivities, constraints and opportunities for change and improvement towards an increased level of resilience.

\subsection{The APSFarmmodelling approach}

APSFarm (also in Power et al., 2011) is the extended whole farm configuration of the farming systems model APSIM (Keating et al., 2003). The motivation to develop APSFarm originated from the need to simulate the impacts (i.e. economic, financial, environmental), of the alternative allocation of limited resources (e.g. land, labour, time, irrigation water, livestock, machinery, and finance), across a number of alternative farm enterprises at the whole farm 
level. APSFarm is included in the 7.2 (and higher) releases of the APSIM model available at http://www.apsim.info.

Here we used APSFarm in a participatory action research (PAR) study to support discussions on the design of more profitable and resilient farm businesses with groups of collaborating farmers. Our PAR approach involves interviews and discussions with case study farmers and their consultants with the objective of (i) describing the farm business i.e. resources, assets, rules and decision making processes farmers apply when managing their farm; (ii) identifying problems and potential opportunities for improvement; and (iii) use the APSFarm model to research specific questions via What if? scenario analyses e.g. climate, price, management, and to quantify trade-offs between competing farmers' objectives e.g. profit and economic risk. Simulation outputs are then used to inform discussions with the participating farmers. Outcomes from these discussions include farmers and researchers having an increased understanding of the farming system under study, and an increased certainty on the likely costs and benefits from the adoption of alternative adaptation options.

\subsection{The APSFarm model}

A key difference with APSIM is that in APSFarm the management of the farming system is modelled as a set of state and transition networks, or finite state automata. In APSFarm, each field has a current state e.g. fallow, wheat, sorghum, etc., and 'rules' allow the transitions between adjacent states, e.g. wheat - fallow - sorghum. These rules represent the capacity e.g. availability of machinery, land, labour; capabilities e.g. agronomic and technical skills; and preferences e.g. farm business strategies, risk attitude, of the farm manager. Rules are expressed as a Boolean value (true for feasible, false for otherwise), and can also take real values, e.g. higher values can represent the desirability of a particular action. Each day, the model examines all paths leading away from the current state to adjacent states, and if the product of all rules associated with a path is non-zero, it becomes a candidate for action. The highest ranking path is taken, and the process repeats until nothing more can be done for that day. Rules can represent farm level criteria, such as sowing windows for each crop, definitions of "break of the season" such as mm of rainfall over a defined period of time, the maximum farm area that could be sown to each crop. Examples of field level criteria include: minimum extractable soil water (ESW, $\mathrm{mm}$ ) required for sowing a crop, definitions of a "sowing opportu-



Fig. 1. Schematic representation of the original farming systems for Farm A-plastic and Farm B-rigid as per interviews with the farm manager. Where, $\mathrm{F}$ is fallow, SF summer fallow, WF winter fallow, $S_{1,2, \ldots}$ and $W_{1,2, \ldots}$ represent sorghum and wheat crops, respectively, having contrasting managements, and where $C$ is chickpea and $\mathrm{M}$ is maize.

nity", cropping history, soil type i.e. plant available water capacity (PAWC), the level of ground cover, etc.

The results from actions having economic implications (e.g. variable costs from the use of fertilisers, the need for seeds for planting a crop, or the profits from harvesting a crop), are calculated based on a list of expected costs and prices provided by the participating farmers. Fixed farm operational costs are also obtained from the participating farmer and used in the calculation of farm profits (i.e. before tax). Therefore, outputs from APSFarm include, but are not limited to, production measures e.g. yields and crop areas; economic measures e.g. production costs, crop gross margins, economic risk, and farm annual profit; efficiency measures e.g. crop and whole farm water use efficiency; and environmental measures e.g. deep drainage, runoff, and erosion.

\subsection{Case studies and simulated scenarios}

The managers from two farm businesses having contrasting levels of plasticity in their tactics and strategies, i.e. Farmer A-plastic, and Farmer B-rigid, were interviewed, and a complete description of the tactical and strategic management of their farms was obtained (Fig. $1 \mathrm{a}$ and $\mathrm{b}$, and Tables 1 and 2 ).

Farmer A-plastic (Fig. 1a) manages a rain-fed 2000 ha no-till cropping farm, subdivided into ten management units, near Emerald, Central Queensland, Australia $\left(-23.53^{\circ} \mathrm{S}, 148.16^{\circ} \mathrm{E}\right)$. Farmer

Table 1a

Farm level variables and their threshold values in APSFarm as per interview with the manager of Farm A-plastic.

\begin{tabular}{|c|c|c|c|c|}
\hline & \multicolumn{4}{|c|}{ Farm level variables } \\
\hline & Sowing window & $\begin{array}{c}\text { Sowing } \\
\text { opportunity* } \\
(\mathrm{mm})\end{array}$ & $\begin{array}{c}\text { Area to sow } \\
(\%)\end{array}$ & $\begin{array}{c}\text { Work capacity } \\
(\mathrm{ha} / \mathrm{h})\end{array}$ \\
\hline \multicolumn{5}{|l|}{ Crops } \\
\hline Spring sorghum & 15 Aug - 31 Oct & 25 & 10 & \multirow{8}{*}{$13-23$} \\
\hline Early sorghum & $1 \mathrm{Nov}-15 \mathrm{Dec}$ & 25 & 30 & \\
\hline Sorghum & $16 \mathrm{Dec}-15 \mathrm{Feb}$ & 25 & 80 & \\
\hline Late sorghum & $16 \mathrm{Feb}-28 \mathrm{Feb}$ & 15 & 30 & \\
\hline Maize & $15 \mathrm{Jan}-28 \mathrm{Feb}$ & 25 & 20 & \\
\hline Wheat & $31 \mathrm{Mar}-30$ Jun & 25 & 80 & \\
\hline Chickpea & 1 May - 15 Jun & No rule & 40 & \\
\hline Cover crop & After 30 Jun & 15 & 30 & \\
\hline
\end{tabular}


Table 1b

Field level rules, variables and their threshold values in APSFarm as per interview with the manager of Farm A-plastic.

\begin{tabular}{|c|c|c|c|c|}
\hline & \multicolumn{4}{|c|}{ Field level variables } \\
\hline & \multicolumn{2}{|c|}{ Soil water } & \multirow[t]{2}{*}{ History $^{\mathrm{c}}$} & \multirow[t]{2}{*}{ Soil type $(\mathrm{mm})^{\mathrm{d}}$} \\
\hline & $(\mathrm{mm})^{\mathrm{a}}$ & $(\mathrm{mm} / \mathrm{mm})^{\mathrm{b}}$ & & \\
\hline \multicolumn{5}{|l|}{ Crops } \\
\hline Spring sorghum & $>100$ & & 3 & \\
\hline Early sorghum & $>80$ & & 3 & \\
\hline Sorghum & $>80$ & & 3 & \\
\hline Late sorghum & $>60$ & & 3 & \\
\hline Maize & $>110$ & & 3 & $>140$ \\
\hline Wheat & $>80$ & & 3 & \\
\hline Chickpea & $>100$ & $>0.7$ & 1 & \\
\hline
\end{tabular}

a Available plant water in the whole soil profile.

b Available plant water for moisture seeking chickpea in the 0.1-0.2 m soil layer.

c Maximum number of years of monoculture.

d Soil plant available water capacity $(\mathrm{mm})$.

A-plastic was selected for this study as he has been member of a farming systems research and development project for more than eight years and an extensive data set on soil properties, crop sequences, production costs and yields was already available. As most farmers in his region, Farmer A-plastic is highly opportunistic in the tactical and strategic management of his farm, meaning that he will constantly monitor environmental and market conditions for opportunities to sow a crop or change practice and tactics aiming to maximise profits and ground cover. Farmer A-plastic can be defined as highly environmentally contingent. His farm comprises three major soil types of contrasting plant available water capacity i.e. low $120 \mathrm{~mm}$ on $30 \%$ of the farm, medium $150 \mathrm{~mm}$ on $40 \%$ of the farm, and high $180 \mathrm{~mm}$ on the remaining $30 \%$. In average the farmer cultivates c.a. one third of the area to winter crops i.e. wheat and chickpea, and two thirds to summer crops i.e. sorghum and maize, though this ratio could vary to up to $80 \%$ of the area to each of the individual enterprises (except maize and chickpea) depending on relative prices and seasonal conditions. Over the last few years the cropping intensity was rather high, though variable, in the range of 80 to $100 \%$. Work capacity varies depending on the farm activity from 13 to 23 ha/h (Table 1a). Fig. 1 and Tables $1 \mathrm{a}$ and $1 \mathrm{~b}$, describe the key dynamics, rules and threshold values that define the farming system. Fig. 1a, shows the alternative states in which any particular management unit (i.e. field) can be found, while the arrows represent the rules that need to be met for a transition to
Table 2b

Field level rules, variables and their threshold values in APSFarm as per interview with the manager of Farm B-rigid.

\begin{tabular}{lllll}
\hline & \multicolumn{3}{l}{ Field level variables } \\
\cline { 2 - 5 } & Soil water & $\begin{array}{l}\text { Crop } \\
\text { history }\end{array}$ & $\begin{array}{l}\text { Ground } \\
\text { cover }(\%)\end{array}$ \\
\cline { 2 - 5 } & & & \\
\hline Crops & & & & \\
Short fallow sorghum & $>100$ & & 2 & \\
Long fallow sorghum & $>100$ & & 2 & \\
Short fallow early wheat & $>80$ & 0.8 & 2 & $>30$ \\
Long fallow early wheat & $>80$ & 0.8 & 2 & \\
Short fallow wheat & $>80$ & 0.8 & 2 & \\
Long fallow wheat & $>80$ & 0.8 & 2 & \\
Late wheat & $>80$ & 0.8 & 2 & \\
Chickpea & $>80$ & 0.8 & 1 &
\end{tabular}

a Available plant water in the whole soil profile.

b Available plant water for moisture seeking wheat and chickpea, i.e. volumetric soil water content in the $0.1-0.2 \mathrm{~m}$ soil layer

c Maximum number of years of monoculture.

occur (Tables 1a and 1b). This farmer grows four crops, i.e. sorghum, maize, wheat and chickpea, though sorghum can be considered as four enterprises having different genotypes, sowing rules, nitrogen managements, sowing windows, and maximum sowing areas i.e. as proportion of the whole farm. For example, spring sorghum is sown between 15th August and 31st of October, if: (i) there is a sowing opportunity i.e. accumulation of at least $25 \mathrm{~mm}$ of rainfall over four consecutive days and there is no rain on the sowing day; (ii) the existing area sown to spring sorghum does not exceed $10 \%$ of the farm area; (iii) there is more than $100 \mathrm{~mm}$ of available plant water in the soil profile; (iv) sorghum was not grown more than twice in the last three years on that field; and (v) the tractor is available for sowing the crop (Tables $1 \mathrm{a}$ and $1 \mathrm{~b}$ ). In case any of those five rules would not be met, the sowing for spring sorghum would not proceed, and the model would then consider sowing early sorghum after the 1st of November. When more than one crop would be available for sowing at any particular day, the model would assign the use of the tractor to sow first the field having the highest value of soil available water (as per farmer's feedback).

Farmer B-rigid (Fig. 1b, and Tables 2a and 2b) manages a rainfed 3000 ha no-till cropping farm subdivided into 10 management units, near Goondiwindi, Southern Queensland, Australia ( -28.55 ${ }^{\circ} \mathrm{S}, 150.31^{\circ} \mathrm{E}$ ). Farmer $B$-rigid is managed by a well-known private consultant from the Goondiwindi region that maintains an excel-

Table 2a

Farm level rules, variables and their threshold values in APSFarm as per interview with the manager of Farm B-rigid.

\begin{tabular}{|c|c|c|c|c|}
\hline & \multicolumn{4}{|c|}{ Farm level variables } \\
\hline & Sowing window & $\begin{array}{c}\text { Sowing } \\
\text { opportunity* } \\
(\mathrm{mm})\end{array}$ & $\begin{array}{c}\text { Area to } \\
\text { sow }^{*} \\
(\%)\end{array}$ & $\begin{array}{c}\text { Work } \\
\text { capacity }^{*} \\
(\mathrm{ha} / \mathrm{h})\end{array}$ \\
\hline \multicolumn{5}{|l|}{ Crops } \\
\hline Short fallow sorghum & $1 \mathrm{Sep}-16 \mathrm{Dec}$ & 20 & 20 & \multirow{8}{*}{$8-20$} \\
\hline Long fallow sorghum & $1 \mathrm{Dec}-16 \mathrm{Dec}$ & 20 & 80 & \\
\hline Short fallow early wheat & $26 \mathrm{Apr}-7$ May & Deep sowing & 20 & \\
\hline Long fallow early wheat & 26 Apr - 7 May & Deep sowing & 20 & \\
\hline Short fallow wheat & 8 May - 1 Jun & Deep sowing & 80 & \\
\hline Long fallow wheat & 8 May - 1 Jun & Deep sowing & 80 & \\
\hline Late wheat & 2 Jun -9 Jun & Deep sowing & 10 & \\
\hline Chickpea & 14 May - 30 May & Deep sowing & 20 & \\
\hline
\end{tabular}


lent database of farm records including soils, climate, farm inputs and outputs. The manager of Farm B-rigid, is less opportunistic in his tactics and strategies and tends to follow a relatively more fixed rotation of cropping enterprises. Farm B-rigid can be defined as more "calendar-driven". The farm also comprises three major soil types of contrasting plant available water capacity i.e. low $140 \mathrm{~mm}$ on $20 \%$ of the farm, medium $160 \mathrm{~mm}$ in $60 \%$ of the farm, and high $180 \mathrm{~mm}$ in the remaining $20 \%$. In average the farmer crops c.a. two thirds of the area to winter crops i.e. wheat and chickpea, and one third to summer crops i.e. sorghum, this ratio is rather constant irrespective of changes in relative prices or seasonal conditions. The cropping intensity is consistently close to $80 \%$. There are a number of different sorghum and wheat enterprises characterised by contrasting fallow lengths and sowing windows, encompassing different genotypes, nitrogen managements, and allocated farm areas (Tables 2a and 2b).

Even though the difference in management strategies between Farm A-plastic and Farm B-rigid are significant, both farm managers are considered leading farmers in their respective regions, operating at the upper end of achievable productivity. These farmers constantly test and adopt the latest technologies available, participate in well organised and supported farming systems projects, access and use technical and climate risk management information and climate risk management tools from a range of reliable sources (http://www.longpaddock.qld.gov.au/; http://www.climatekelpie.com.au/). Therefore, these farms are already well buffered against the high level of environmental variability in which they operate, so small differences in performance could be expected from different scenarios tested here. A key difference between the two managements though, is that Farm B-rigid has a more risk-averse management strategy preferring to achieve higher yields with fewer crops i.e. lower crop intensity, in a way to minimise the chance of negative returns i.e. down side risk or probability of a negative return.

In order to compare plastic and rigid farm businesses within each agro-ecology, two additional (hypothetical) farm businesses were described with the help of expert local agronomists i.e. A Farmer A-rigid, and a Farmer B-plastic, and simulated with APSFarm. To create a hypothetical Farmer A-rigid we: (i) increased the minimum value of available soil water required to sow a crop i.e. a more risk averse strategy; (ii) reduced the maximum area of land that any particular crop could be sown i.e. less opportunistic; and (iii) eliminated the technical possibility of deep sowing chickpea crops i.e. sowing into subsoil moisture when the top $0.1 \mathrm{~m}$ of soil is dry.

To create a hypothetical Farmer B-plastic we: (i) reduced the minimum value of available soil water required to sow a crop i.e. a less risk averse strategy; (ii) increased the maximum area of land that any particular crop could be sown i.e. more opportunistic; (iii) both wheat and chickpea had the technical possibility of deep sowing into subsoil moisture; and (iv) the rotational system was relaxed by allowing double cropping to occur i.e. two consecutive crops grown after a very short fallow.

The four farm businesses were implemented in APSFarm and the model outputs (over 20 years of historical data) were validated against farmers' estimates of expected yields, the advice from expert local agronomists, and for the case of Farm A-plastic from two long term rotation trials (not shown - available from the authors upon request).

The stressor, in the form of climate-change projections, was derived from likely Special Report on Emissions Scenarios (SRES) projections for 2030 (A2 and A1T), and 2070 (A2 and A1F) (IPCC, 2007), and the outputs from the a single global circulation model HadCM3, by modifying monthly values in temperature and rainfall downscaled to the daily series of 100 years of climatology (Crimp et al., 2007). The scenarios introduced a 4.2, 6.3, 9.3, and $14.3 \%$ reduction in annual rainfall, and a $0.45,0.8,1.5$, and $2.48^{\circ} \mathrm{C}$ increase in median annual temperature, respectively. The methodology assumes no changes in rainfall or temperature variability, though the natural variability in the historical records was preserved. $\mathrm{CO}_{2}$ levels were unique to each projection, i.e. A2 year 2030 $\left(451 \mathrm{ppm} \mathrm{CO} \mathrm{CO}_{2}\right)$ and year $2070\left(635 \mathrm{ppm} \mathrm{CO} \mathrm{CO}_{2}\right)$, and $\mathrm{A} 1 \mathrm{~T}$ year 2030 $\left(440 \mathrm{ppm} \mathrm{CO} \mathrm{CO}_{2}\right)$, and $\mathrm{A} 1 \mathrm{~F}$ year $2070\left(716 \mathrm{ppm} \mathrm{CO}_{2}\right)$.

Impacts and sensitivities of the four different farm strategies were evaluated in terms of simulated changes on individual crop yields (annual median values over the whole farm are presented), changes in cropping intensity, changes in the mix of crop enterprises, enterprise diversification, farm profits and down side risks.

\section{Results}

\subsection{Farm crop yields}

Crop mixes and crop yields within each farm responded differently to the projected changes in climate (Figs. 2-5). For the original Farm A-plastic, median sorghum and maize yields were reduced by $19 \%$ and $34 \%$, respectively, in response to the warmer and drier conditions assumed by the 2070 A1F scenario (Fig. 2a and b). For the same strategy and scenario wheat and chickpea yields were increased by 51 and 45\%, respectively, (Fig. 2c and d). A more rigid management strategy (Farm A-rigid), resulted in larger reductions in median sorghum yield (26\%) and similar (33\%) maize yield losses for the same future scenario (Fig. 3). Increases in mean wheat and chickpea yields in response to climate change were also lower than under the more plastic strategy (i.e. increases of 22 and $42 \%$, respectively), (Fig. 3c and d).

For the original Farm B-rigid, median sorghum and chickpea yields were reduced by $9 \%$ and $3 \%$, respectively, in response to the assumed climate from the 2070 A1F scenario, (Fig. 4a and c). For the same strategy and scenario wheat yields were increased by 4\%, (Fig. 4b). For the hypothetical Farm B-plastic, median sorghum, chickpea, and wheat yields were reduced by $31 \%, 15 \%$ and $1 \%$, respectively, i.e. comparing the baseline with the 2070 A1F scenario, (Fig. 5a-c).

\subsection{Cropping intensity and cropping mix}

Cropping intensities and cropping mix were also affected by the climate change scenarios, though differently across crops, farm business strategies and regions (see number of simulated crops at the top of Figs. 2-5).

For the original Farm A-plastic, cropping intensity was reduced by $19 \%$ and $27 \%$ for the 2030 A1T and 2070 A1F scenarios, respectively, (Fig. 2a-d). Relative to the baseline scenario, summer cropping increased by $16 \%$ and $8 \%$, and winter cropping decreased by $28 \%$ and $15 \%$, for the $2030 \mathrm{~A} 1 \mathrm{~T}$ and $2070 \mathrm{~A} 1 \mathrm{~F}$ scenarios, respectively, (Fig. 2a-d). For the hypothetical Farm A-rigid, cropping intensity was reduced by $4 \%$ and $15 \%$ for the 2030 A1T and 2070 A1F scenarios, respectively, (Fig. 4a-d). Relative to the baseline scenario, summer cropping increased by $5 \%$ and $3 \%$, and winter cropping decreased by $14 \%$ and $8 \%$, for the $2030 \mathrm{~A} 1 \mathrm{~T}$ and $2070 \mathrm{~A} 1 \mathrm{~F}$ scenarios, respectively, (Fig. 4a-d).

For the original Farm B-rigid, cropping intensity was reduced by $9 \%$ and $26 \%$ for the 2030 A1T and 2070 A1F scenarios, respectively, (Fig. 4a-c). Relative to the baseline scenario, summer cropping decreased by $11 \%$ and $28 \%$, and winter cropping increased by 5 and $13 \%$, for the $2030 \mathrm{~A} 1 \mathrm{~T}$ and $2070 \mathrm{~A} 1 \mathrm{~F}$ scenarios, respectively, (Fig. 4a-c). For the hypothetical Farm B-plastic, cropping intensity was reduced by $8 \%$ and $16 \%$ for the 2030 A1T and 2070 A1F scenarios, respectively, (Fig. 5a-c). Relative to the baseline scenario, summer cropping decreased by $8 \%$ and $30 \%$, and winter cropping increased by 3 and 10\%, for the 2030 A1T and 2070 A1F scenarios, respectively, (Fig. 5a-c). 

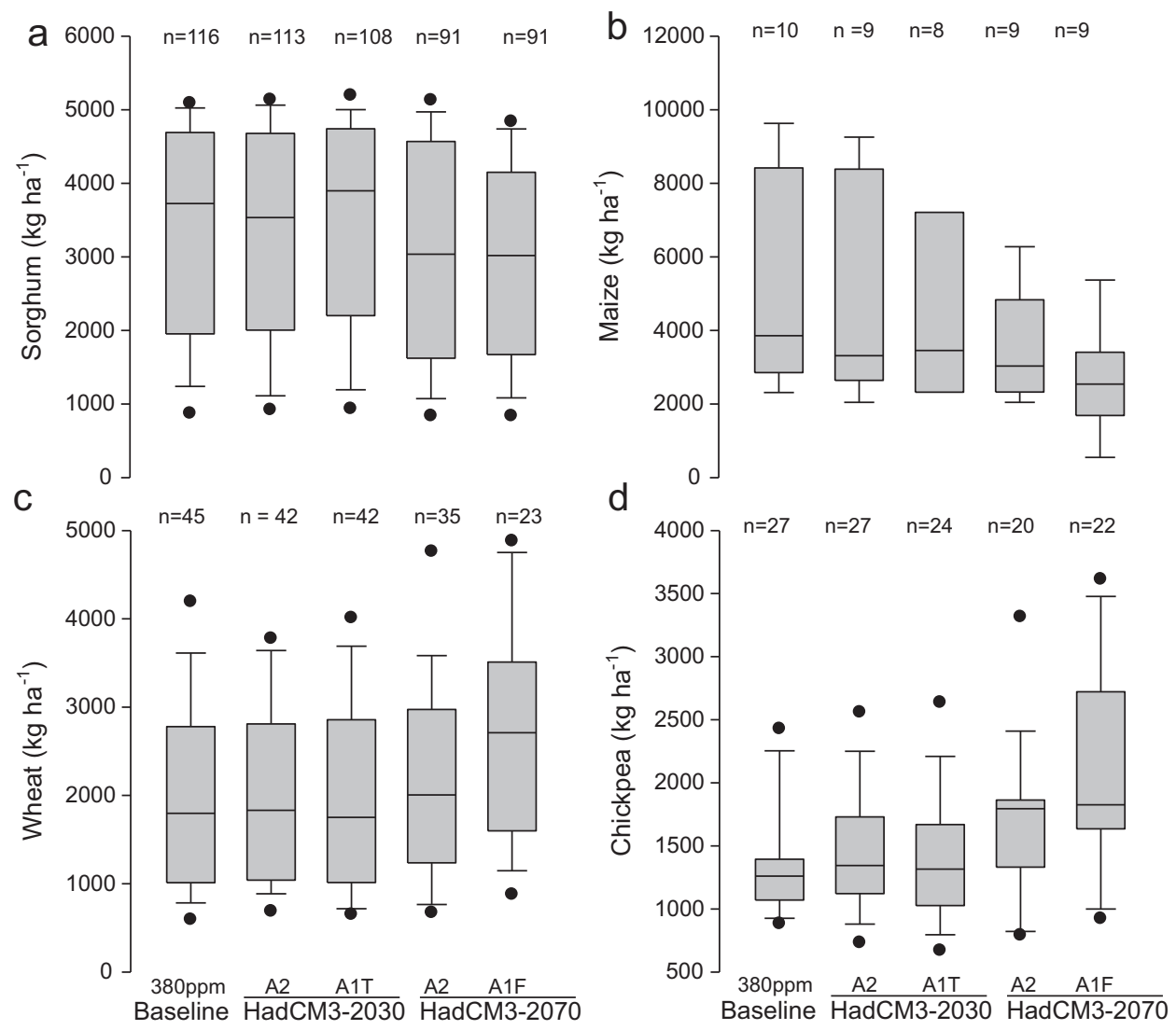



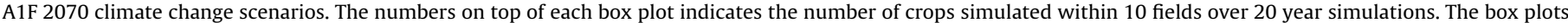
show the minimum and maximum observed values (filled circles), the 5th, 25th, 50th, 75th, and 95th percentiles.

Table 3

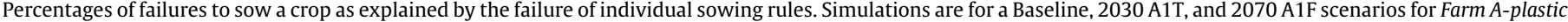
Bold numbers indicate an increase in the percentage relative to the baseline scenario.

\begin{tabular}{|c|c|c|c|c|c|c|}
\hline & Crop & Available soil water ${ }^{\mathrm{a}}$ & Work capacity $^{\mathrm{b}}$ & Area sown ${ }^{c}$ & Sowing opportunity ${ }^{\mathrm{d}}$ & Crop history $^{\mathrm{e}}$ \\
\hline \multirow[t]{7}{*}{ Baseline } & Wheat & 33 & 2 & 0 & 47 & 0 \\
\hline & Chickpea & 37 & 2 & 10 & 4 & 2 \\
\hline & Maize & 31 & 6 & 6 & 41 & 0 \\
\hline & Spring sorghum & 38 & 2 & 0 & 42 & 4 \\
\hline & Early sorghum & 37 & 8 & 0 & 45 & 4 \\
\hline & Sorghum & 35 & 8 & 0 & 49 & 6 \\
\hline & Late sorghum & 23 & 8 & 0 & 48 & 7 \\
\hline \multirow[t]{7}{*}{$2030 \mathrm{~A} 1 \mathrm{~T}$} & Wheat & 33 & 2 & 0 & 47 & 0 \\
\hline & Chickpea & 38 & 1 & 7 & 30 & 2 \\
\hline & Maize & 32 & 6 & 0 & 41 & 0 \\
\hline & Spring sorghum & 38 & 1 & 4 & 42 & 3 \\
\hline & Early sorghum & 37 & 7 & 0 & 46 & 4 \\
\hline & Sorghum & 36 & 8 & 0 & 50 & 5 \\
\hline & Late sorghum & 23 & 9 & 0 & 51 & 5 \\
\hline \multirow[t]{7}{*}{$2070 \mathrm{~A} 1 \mathrm{~F}$} & Wheat & 35 & 1 & 0 & 46 & 0 \\
\hline & Chickpea & 36 & 0 & 8 & 31 & 4 \\
\hline & Maize & 31 & 7 & 7 & 42 & 0 \\
\hline & Spring sorghum & 40 & 1 & 4 & 43 & 5 \\
\hline & Early sorghum & 37 & 6 & 0 & 49 & 6 \\
\hline & Sorghum & 34 & 7 & 0 & 50 & 7 \\
\hline & Late sorghum & 23 & 11 & 0 & 51 & 11 \\
\hline
\end{tabular}

a Available plant water in the whole soil profile.

b Maximum farm area the farmer can crop in one day. The farmer will have different work capacity for different farm activities.

c Maximum area to be sown to each crop as \% of the whole farm.

d Required rainfall to be accumulated within four consecutive days for a successful sowing.

e Maximum number of years of monoculture. 

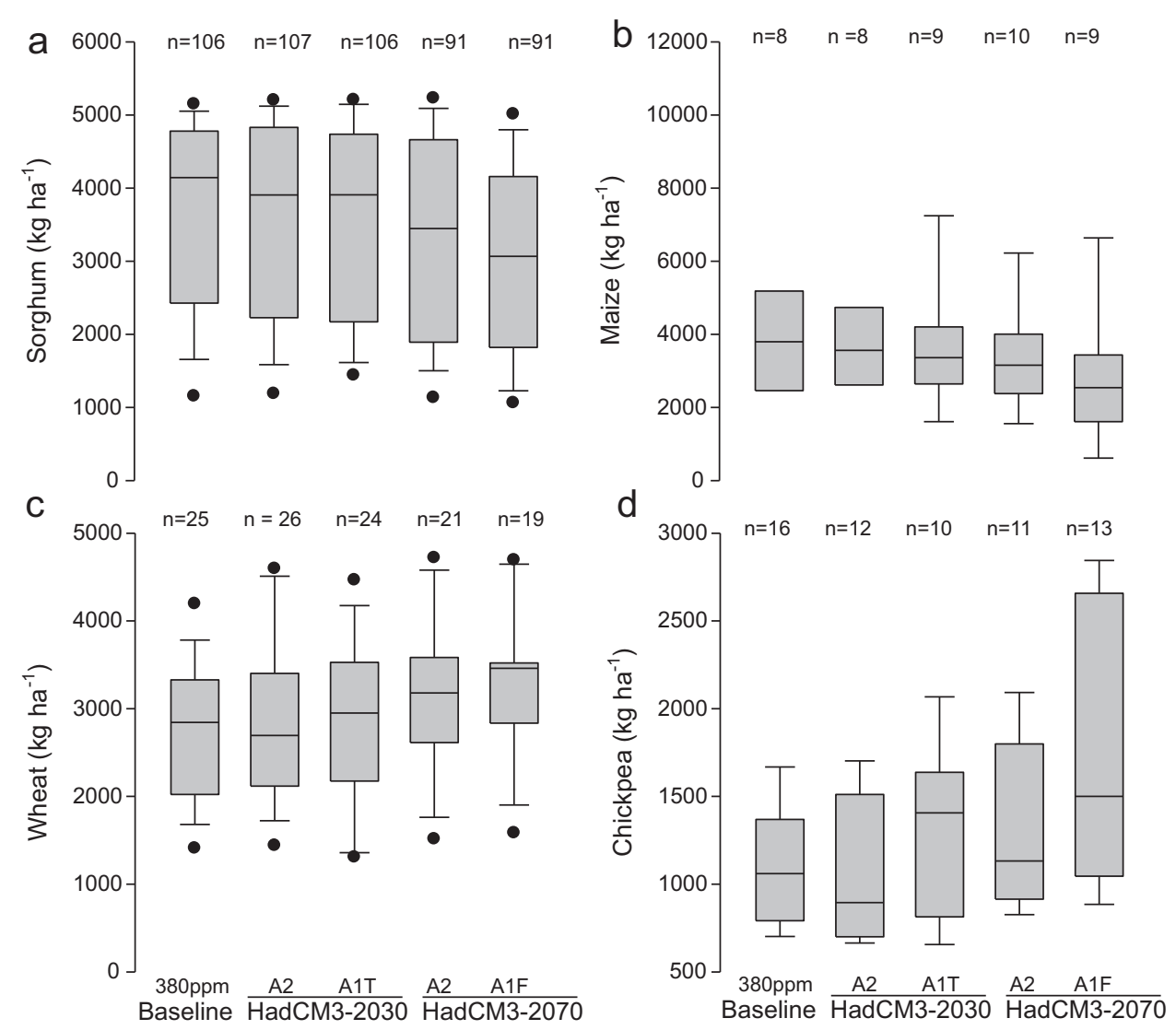

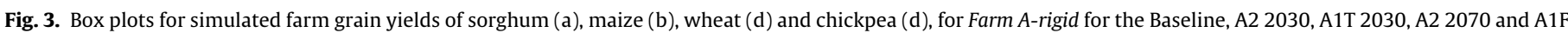

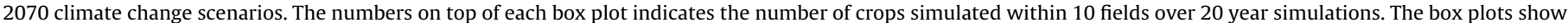
the minimum and maximum observed values (filled circles), the 5th, 25th, 50th, 75th, and 95th percentiles.

The impact of the climate change scenarios on the simulated cropping intensity and crop mix were explained by changes in the failure of individual sowing rules i.e. availability of soil water at sowing, availability of machinery (work capacity), maximum area sown to any particular crop, sowing opportunity, and crop history i.e. the maximum number of years of monoculture (Tables 3 and 4).

For Farm A-plastic reductions in winter cropping were driven by an increase in the number of failures to sow due to (i) lack of a sowing opportunities (in particular for chickpea), and (ii) low values of available soil water. In the model a sowing opportunity for chickpea was defined by the availability of soil humidity for deep sowing, i.e. at least $70 \%$ of plant available water capacity at $0.15 \mathrm{~m}$; for wheat a sowing opportunity was defined as the accumulation of at least $20 \mathrm{~mm}$ of rainfall over five consecutive days (Table 3 ). Reductions in summer cropping were also affected by reductions in the number of sowing opportunities, and as the cropping system became more summer dominated, by crop history, maximum areas sown, and availability of machinery (Table 3 ).

In Farm B-rigid reductions in summer cropping (sorghum) were primarily driven by an increase in the number of failures to sow due to lack of sowing opportunities (Table 4).

\subsection{Farm profits}

Simulated annual operating returns (AU\$/ha) were also affected differently by the climate change scenarios, between farm business strategies, regions and simulated scenarios (Figs. 6 and 7). For Farm $A$ the more flexible farm business strategy was clearly more advantageous for the baseline and A2 2030 scenario (a scenario of warmer and marginal rainfall change). Under condition of more significant rainfall decline (e.g. A1T 2030), the more flexible strategy provided a smaller benefit, to the point that tended to become counterproductive for the A1F 2070 scenario (Fig. 6e). For Farm B instead, a more plastic farm business strategy would be more advantageous for all simulated scenarios (Fig. 7a-e).

Cumulative profits, at the end of 20 year simulated period for each scenario analysed, indicated that the plastic strategy was always more profitable. For Farm $A$ the difference in cumulative profits, over 20 years, between the plastic and rigid strategies ranged from AU\$1104/ha, for the Baseline scenario, to AU\$293/ha for the A1T 2030 scenario. For Farm B the difference in cumulative profits, over 20 years, between the plastic and rigid strategies ranged from AU\$996/ha, for the A2 2070 scenario, to AU\$690/ha for the Baseline scenario.

Economic risk (i.e. down side risk) was mostly unaffected by the climate change scenarios, and farm business strategies. For Farm Aplastic the values of down side risk were $28 \%, 29 \%, 29 \%, 33 \%$ and 35\% for the Baseline, A2 2030, A1T 2030, A2 2070 and A1F 2070, respectively; versus $29 \%, 31 \%, 32 \%, 38 \%$, and $39 \%$ for the Baseline, A2 2030, A1T 2030, A2 2070 and A1F 2070, respectively. For Farm $B$-plastic the values of down side risk were $26 \%, 24 \%, 26 \%, 21 \%$ and 26\% for the Baseline, A2 2030, A1T 2030, A2 2070 and A1F 2070, respectively; versus down side risk values of $21 \%, 23 \%, 23 \%, 24 \%$, and 32\% for the Baseline, A2 2030, A1T 2030, A2 2070 and A1F 2070 , respectively.

\section{Discussion}

These findings provide evidence that for environments and farm business structures similar to those studied here, farm managers that apply a higher level of plasticity in their tactical and strategic management are likely to achieve higher levels of farm profit 

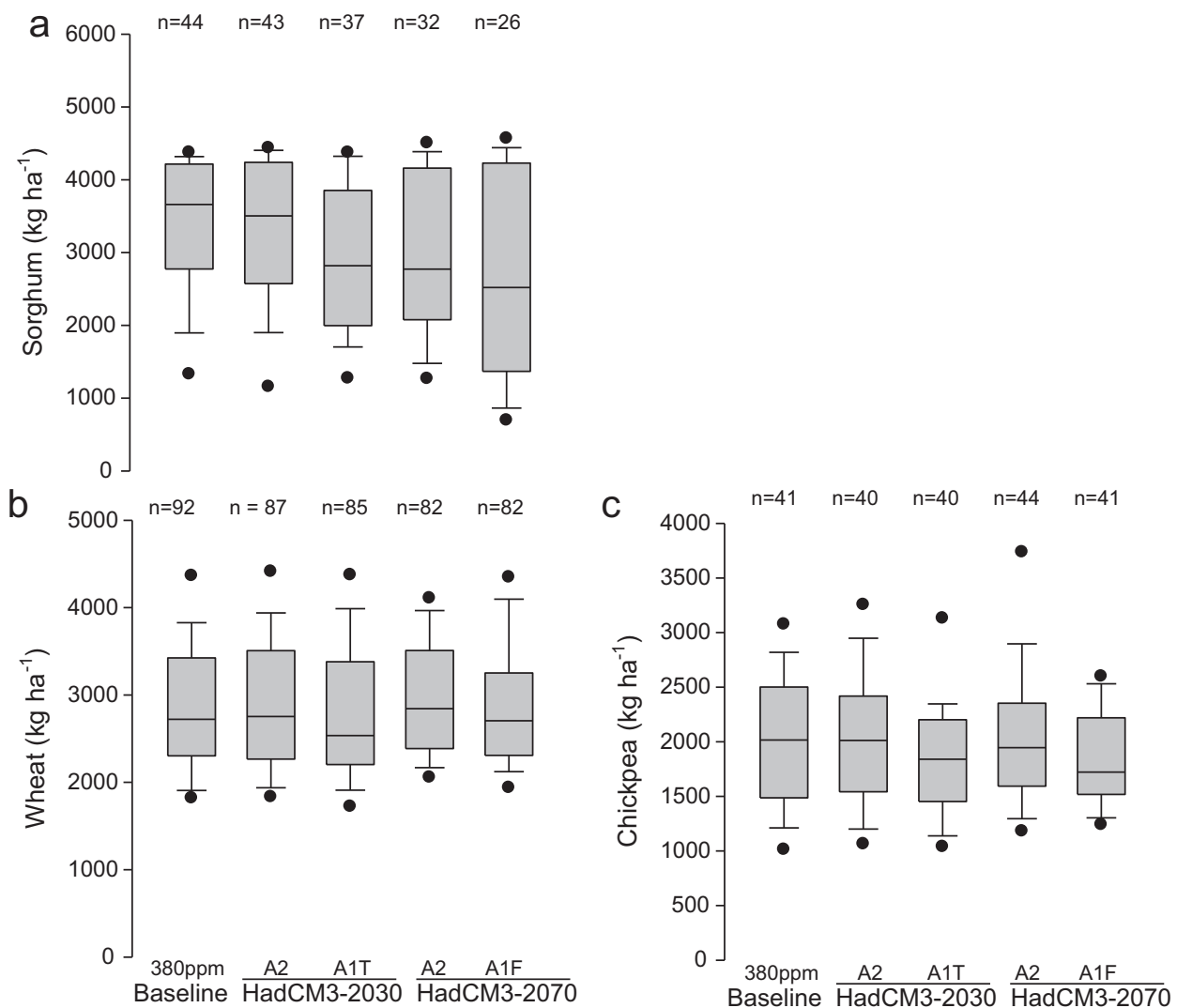

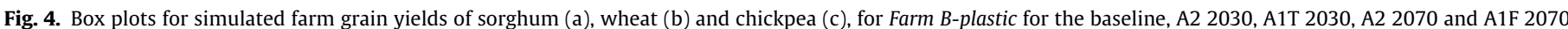

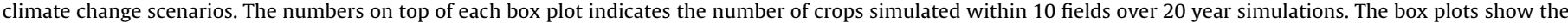
minimum and maximum observed values (filled circles), the 5th, 25th, 50th, 75th, and 95th percentiles.

and resilience when exposed to a stressor such as climate change. However, in the tested case studies the magnitude of the benefit of a more plastic strategy seemed to depend on the intensity of the stress imposed on the system. For Farm A, the differences between a plastic and rigid strategy tended to disappear for the driest/warmest scenario. This result resembles the presence of a tipping point in the system, for plasticity to be a beneficial attribute in the management of the business. As this tipping point is reached, more important transformational changes might be needed to more dramatically reframe the business strategy. Our findings also highlight benefits from the development and application of more integrative and interdisciplinary systems technologies to evaluate impacts, and opportunities for adaptation to climate variability and change.

\subsection{Plasticity as an important attribute of resilient systems}

Ecologists have long identified that phenotypic plasticity is a key element in the functioning of organisms in variable environments (DeWitt et al., 1998). Theories of phenotypic plasticity all deal with adaptation to variable environments. Here we used some of these concepts to argue that, as in natural systems, more plastic farm management tactics and strategies, (i.e. managers that respond adaptively or opportunistically to "environmental" cues such as climate), enhance resilience and fitness in risky and uncertain environments. For the two environments studied here, the plastic strategies proved to be more profitable (Figs. 6 and 7), and less risky than the more rigid comparisons. These results show that, in principle, more plastic business designs and decision rules enable farmers to respond better to environmental shifts, thus ensuring the economic viability of the farm business when exposed to externalities. However, the benefit from the more plastic strategies tended to disappear as the stress imposed on the system increased, particularly for the case of Farm A (Fig. 6e).

Even though the presence of variability is necessary for plasticity to be a beneficial attribute in farm businesses, the answer to when or whether a more plastic strategy should be favoured over a more rigid one remains open, as social, personal or practical issues are brought into consideration. The benefit from more plastic over more rigid farm business management strategies are likely to depend on: the level of variability in the operating environment; the nature and impact of the changing variable; the presence of feasible alternative management options; the presence of tradeoffs between competing objectives in the farm business; benefits that outweigh the costs of plasticity; and of course, farmers' preferences.

Rainfall variability in Australia is an important source of variability in the production of food and fibre crops, farm income, and in fact, Australia's farm commodity exports. During the 2002 El Niño drought Australia reduced commodity exports by $3.7 \%$ and economic growth by $0.75 \%$ (ABARE http://www.abare.gov.au), while the economic impact of the 2010-2011 La Niña floods and cyclone Yasi are expected to be $0.5 \%$ of Australia's gross domestic product - about $\$ 6$ billion (http://moneybasics.nab.com.au). In Australia the frequency of widespread droughts is usually of about one per decade, though more frequent and prolonged droughts have been recorded in recent times (Timbal, 2009; Hayman et al., 2010). In response to variability, Australian farmers have developed farming systems that are highly buffered against variations in rainfall. Flexible rules e.g. sowing and crop choice selection, split applications of nitrogen fertilisers, changes in the mix of summer and winter crops, changes in cropping intensities, fallow duration, sup- 

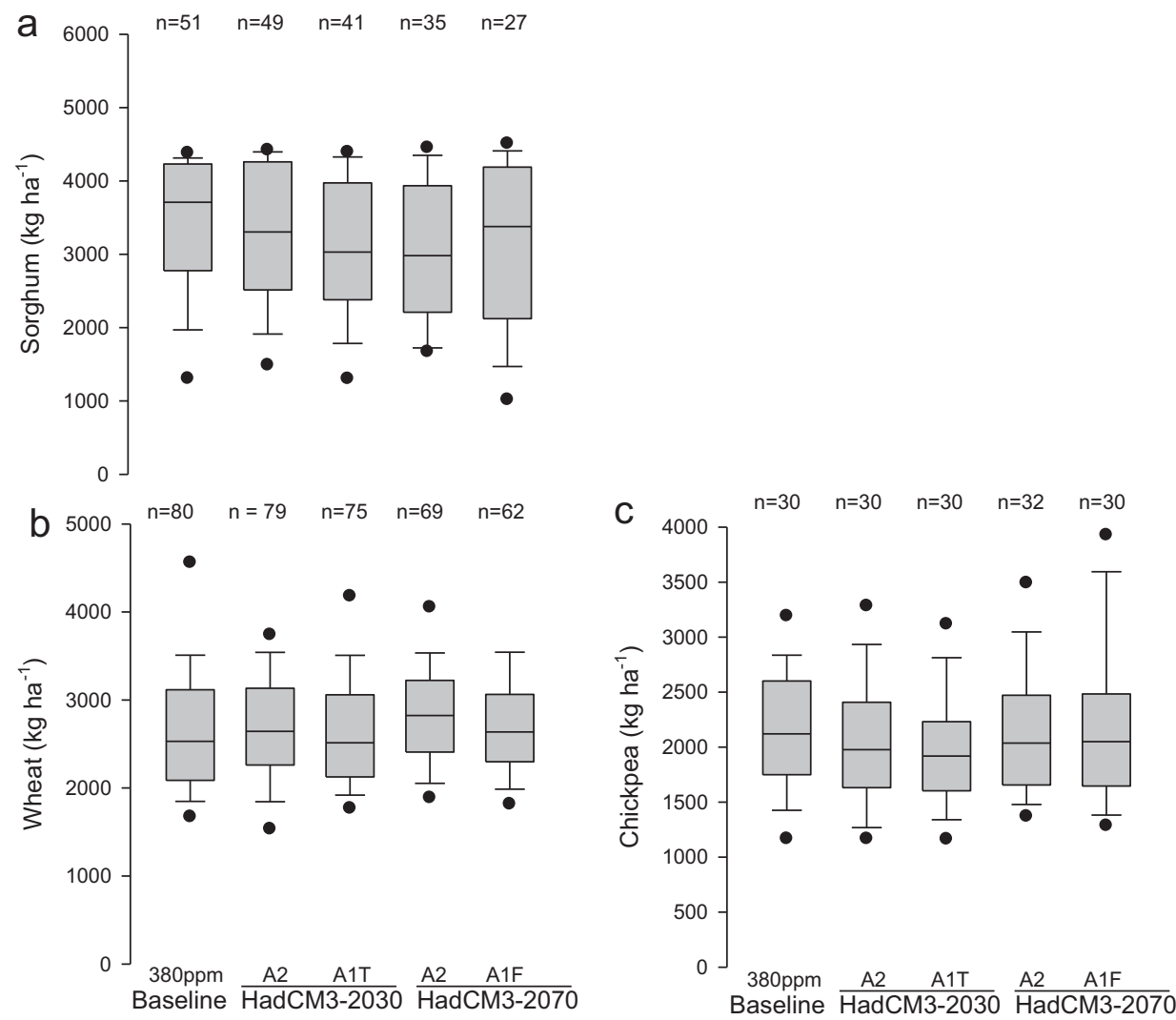

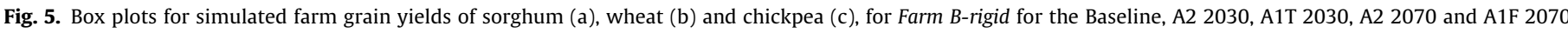


minimum and maximum observed values (filled circles), the 5th, 25th, 50th, 75th, and 95th percentiles.

plementary irrigation, and changes in the allocation of land to grain and grazing enterprises are usually made contingent to observed or expected changes in seasonal and inter decadal climate conditions (Meinke and Stone, 2005). Even though variability is intrinsic to most Australian farming systems, not all farmers adjust their tactics and strategies to match this heterogeneity. From the two examples reported here, even though these farmers are considered above average operators, their farm businesses contrast in the level of plasticity in tactical and strategic management. In Australia, an important cost of plasticity is time (Doole et al., 2009), as a more environmentally contingent management strategy would require frequent monitoring of a number environmental and market clues used to trigger changes on the farming system. Work capacities as indicated in this study (Tables $1 \mathrm{~b}$ and $2 \mathrm{~b}$ ) were obtained during interviews with the participating farmers and represent the required time to perform sowing, spraying, and harvesting activities based on existing machinery and labour. The farm A-Plastic is managed by two young and highly motivated brothers that share the activities on the farm, while farm B-Rigid management is based on the managers preference for minimising loses, though accepting that this might involve missing some of the good opportunities associated with the best seasons.

\subsection{Impacts of climate change: farm crop yields - just half of the story}

Crop farm yields reported in this study are derived from a number of thoroughly tested APSIM crop modules (i.e. sorghum, wheat, chickpea, and maize) (Reyenga et al., 1999; Keating et al., 2003; Asseng et al., 2004) running under APSIM's whole farm systems model configuration. Therefore, the distribution of yields presented in Figs. 2-5 are farm yields, i.e. all the crops grown across the farm- fields over the simulated period. Irrespective of the farm strategy, at Farm A median yields from the summer crops (C4 metabolism) were relatively stable until the 2070 scenarios, while for Farm B, median yields of sorghum were also reduced at the earlier 2030 scenarios. Instead, median yields of the winter crops (C3 metabolism), tended to increase at Farm A, particularly for the 2070 scenarios, while remained largely unaffected at Farm $B$. In general for both Farm $A$ and Farm $B$ the rigid strategies tended to produce higher median yields than the plastic strategy, clearly driven by changes in cropping intensity and crop mix.

The analysis of changes in median farm yields and farm yield variability provided insight on potential adaptation options for the original Farm A-plastic and Farm B-rigid. In the case of Farm A-plastic, maize is a highly opportunistic crop only grown on the best seasons and on the best soils of the farm (Tables 1a and 1b). Fig. 2b shows that in addition to important reductions in median yields, the good seasons i.e. opportunities for high yields tend to disappear indicating the need to revisit the sowing rules for the crop in view of shifts in cropping windows and sowing opportunities. In the case of chickpea, a winter crop that can be sown into deep wet soil using modern moisture seeking sowing technologies (i.e. deep sowing), seems to provide good opportunities for increasing returns in drier autumns, in particular with the reduction in the proportion of wheat crops (i.e. lack of sowing opportunities), as wheat is not deep sown due to its smaller seeds. Though foliar and root diseases usually prevent growing more than one crop of chickpea per field every two or three years, an increased proportion of chickpea in the rotation would increase the risk of erosive summer rains due to the poor ground cover left by the crop after harvest. An interesting adaptation for the region might involve developing technological solutions to make wheat crops germinate and establish on drier top soils e.g. improved deep sowing 
Table 4

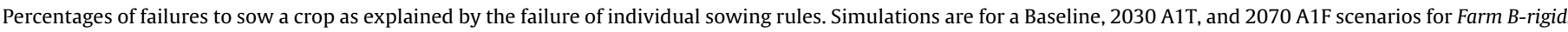
Bold numbers indicate an increase in the percentage relative to the baseline scenario.

\begin{tabular}{|c|c|c|c|c|c|c|}
\hline & Crop & Available soil water ${ }^{\mathrm{a}}$ & Work capacity ${ }^{\mathrm{b}}$ & Area sown ${ }^{c}$ & Sowing opportunity ${ }^{\mathrm{d}}$ & Crop history ${ }^{\mathrm{e}}$ \\
\hline \multirow[t]{10}{*}{ Baseline } & Short fallow early wheat & 3 & 22 & 0 & 34 & 9 \\
\hline & Short fallow wheat & 4 & 17 & 0 & 28 & 10 \\
\hline & Long fallow early wheat & 2 & 18 & 0 & 28 & 7 \\
\hline & Long fallow wheat & 4 & 15 & 0 & 26 & 9 \\
\hline & Late wheat & 6 & 11 & 0 & 68 & 15 \\
\hline & Short fallow early sorghum & 11 & 6 & 0 & 45 & 0 \\
\hline & Short fallow sorghum & 11 & 6 & 0 & 45 & 0 \\
\hline & Long fallow early sorghum & 12 & 7 & 0 & 49 & 0 \\
\hline & Long fallow sorghum & 12 & 7 & 0 & 49 & 0 \\
\hline & Chickpea & 5 & 20 & 21 & 32 & 12 \\
\hline \multirow[t]{10}{*}{$2030 \mathrm{~A} 1 \mathrm{~T}$} & Short fallow early wheat & 4 & 44 & 0 & 54 & 13 \\
\hline & Short fallow wheat & 9 & 39 & 0 & 50 & 13 \\
\hline & Long fallow early wheat & 4 & 44 & 0 & 54 & 13 \\
\hline & Long fallow wheat & 9 & 39 & 0 & 50 & 13 \\
\hline & Late wheat & 11 & 20 & 0 & 95 & 13 \\
\hline & Short fallow early sorghum & 26 & 13 & 0 & 94 & 1 \\
\hline & Short fallow sorghum & 26 & 13 & 0 & 94 & 1 \\
\hline & Long fallow early sorghum & 26 & 13 & 0 & 94 & 1 \\
\hline & Long fallow sorghum & 26 & 13 & 0 & 94 & 1 \\
\hline & Chickpea & 10 & 40 & 34 & 48 & 23 \\
\hline \multirow[t]{10}{*}{$2070 \mathrm{~A} 1 \mathrm{~F}$} & Short fallow early wheat & 3 & 42 & 0 & 51 & 15 \\
\hline & Short fallow wheat & 2 & 35 & 0 & 52 & 16 \\
\hline & Long fallow early wheat & 3 & 42 & 0 & 51 & 15 \\
\hline & Long fallow wheat & 2 & 35 & 0 & 52 & 16 \\
\hline & Late wheat & 2 & 16 & 0 & 96 & 15 \\
\hline & Short fallow early sorghum & 28 & 7 & 0 & 96 & 2 \\
\hline & Short fallow sorghum & 28 & 7 & 0 & 96 & 2 \\
\hline & Long fallow early sorghum & 28 & 7 & 0 & 96 & 2 \\
\hline & Long fallow sorghum & 28 & 7 & 0 & 96 & 2 \\
\hline & Chickpea & 2 & 36 & 30 & 50 & 30 \\
\hline
\end{tabular}

\footnotetext{
a Available plant water in the whole soil profile.

b Maximum farm area the farmer can crop in one day. The farmer will have different work capacity for different farm activities.

c Maximum area to be sown to each crop as \% of the whole farm.

d Required rainfall to be accumulated within four consecutive days for a successful sowing.

e Maximum number of years of monoculture.
}

machinery, and breeding wheat cultivars with longer coleoptiles that would allow the crop to emerge when sown deeper into wetter soil. This will be particularly important for the long term sustainability of increasingly summer rainfall dominated environments, where wheat stubble in no till cropping is required to minimise erosion and increase infiltration during high intensity rainfall events. It is also important to notice that even though farm crop yields were positively or negatively affected by the different climate change scenarios, cropping intensity was consistently reduced. This indicates that farm profitability and sustainability would be most at risk from having fewer crops to harvest and increasing the costs of maintaining fallowed land free of weeds, than from changes in individual crop yields. In summary, these results indicate that recent trends and expected shifts in climate bring challenges and opportunities for these farms. The challenge is how to maintain the cropping intensity of stubble producing winter crops e.g. wheat; and the opportunity how to maximise the use of resources from an increasing concentration of the annual rainfall during the summer months e.g. summer grain and legume intercrops and relay cropping systems are starting to be tested in the region to intensify summer cropping.

\subsection{A case for the need of more integrative and interdisciplinary quantitative approaches}

Even though important advances in the understanding of current and expected impacts (IPCC, 2007; Rosenzweig et al., 2008), and possible options for adaptation (Howden et al., 2007) have been outlined, most impact assessments have been derived from modelling studies on extremely simplified and hypothetical farm- ing systems, usually single crop simulation analyses (Tubiello and Ewert, 2002; Asseng et al., 2004; IPCC, 2007; Garnaut, 2008; Challinor and Wheeler, 2008). This ignores the fact that farmers manage complicated farms rather than just crops, where changes in one enterprise at any point in time can limit options spatially across the farm e.g. due to land, labour or machinery constraints; and temporally across seasons (e.g. due to follow on implications on soil water and nutrients availability, or the need for breaks for pests or diseases between successive crops). A typical example is shown in Tables 3 and 4, where we found that small changes in rainfall seasonality at key times in the cropping calendar (i.e. drier autumns in the environment of Farm $A$, and drier springs in the environment of Farm $B$ - not shown), reduced the number of sowing opportunities for winter and summer crops, respectively This resulted in changes in the proportion of winter and summer crops; increased the demand for labour and machinery during narrower sowing windows and fewer sowing opportunities; reduced the cropping intensity; increased costs due to the need to maintain fallows free of weeds; reduced the availability of wheat stubble to provide ground cover; and reduced the diversity of crops on the farm. These changes in the farming system reduced the profitability of the farms and tended to increase their risk profile. This is the first time the impact of the interactive effects from multiple constraints at the whole farm level were quantified to demonstrate that the interactions between the components in the farming system can be more important than the impacts at the single crop level.

At the farm level, small changes in rainfall seasonality coincident with key activities in the cropping calendar can have important implications on the cropping system, e.g. on the demand for labour, 

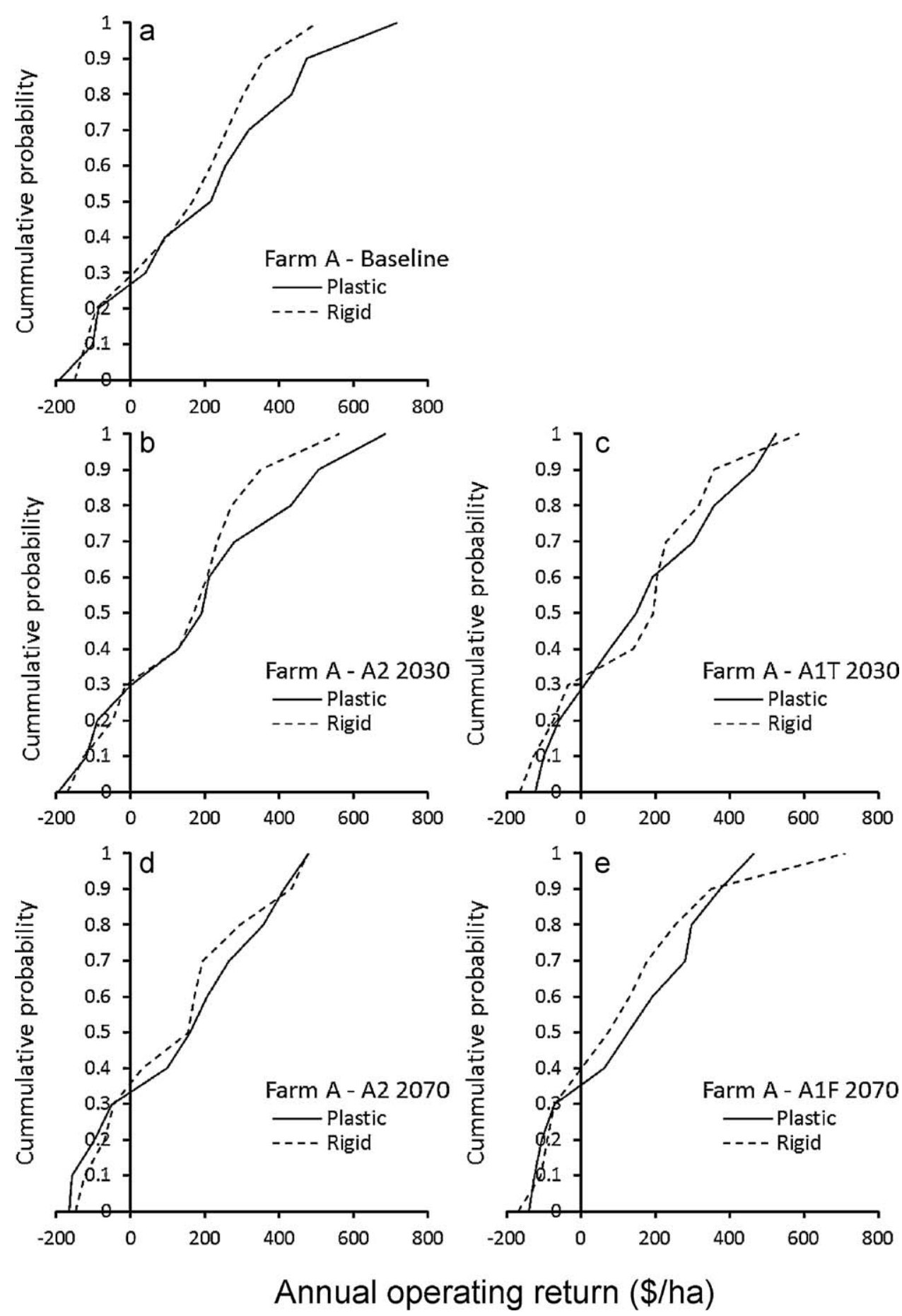

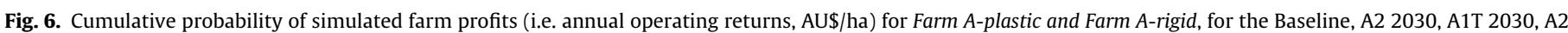
2070 and A1F 2070 climate change scenarios.

for machinery, and final farm output (i.e. ground cover, grain production, cash flow and profits; Tables 3 and 4, and Figs. 6 and 7). Some of these interactions for the farm case studies analysed here are shown in Fig. 8, where we represent the complex nature of farm businesses, including external drivers, internal interactions and the multiple objectives farmers juggle with while managing their business. This shows, as also mentioned by others (Tubiello and Ewert, 2002; Challinor et al., 2009; Meinke et al., 2009), that there is much to be gained from looking at opportunities to adapt and increase the resilience and productivity of farm businesses using whole farm analyses.
Here we presented an example of a participatory modelling integrated assessment that helped us and the participating farmers to:

- better understand the implications from current and expected changes in climate with more realistic implications on the farm business and the farmer

- develop relevant and actionable information that promoted colearning through better informed debates between scientists and practitioners, and 

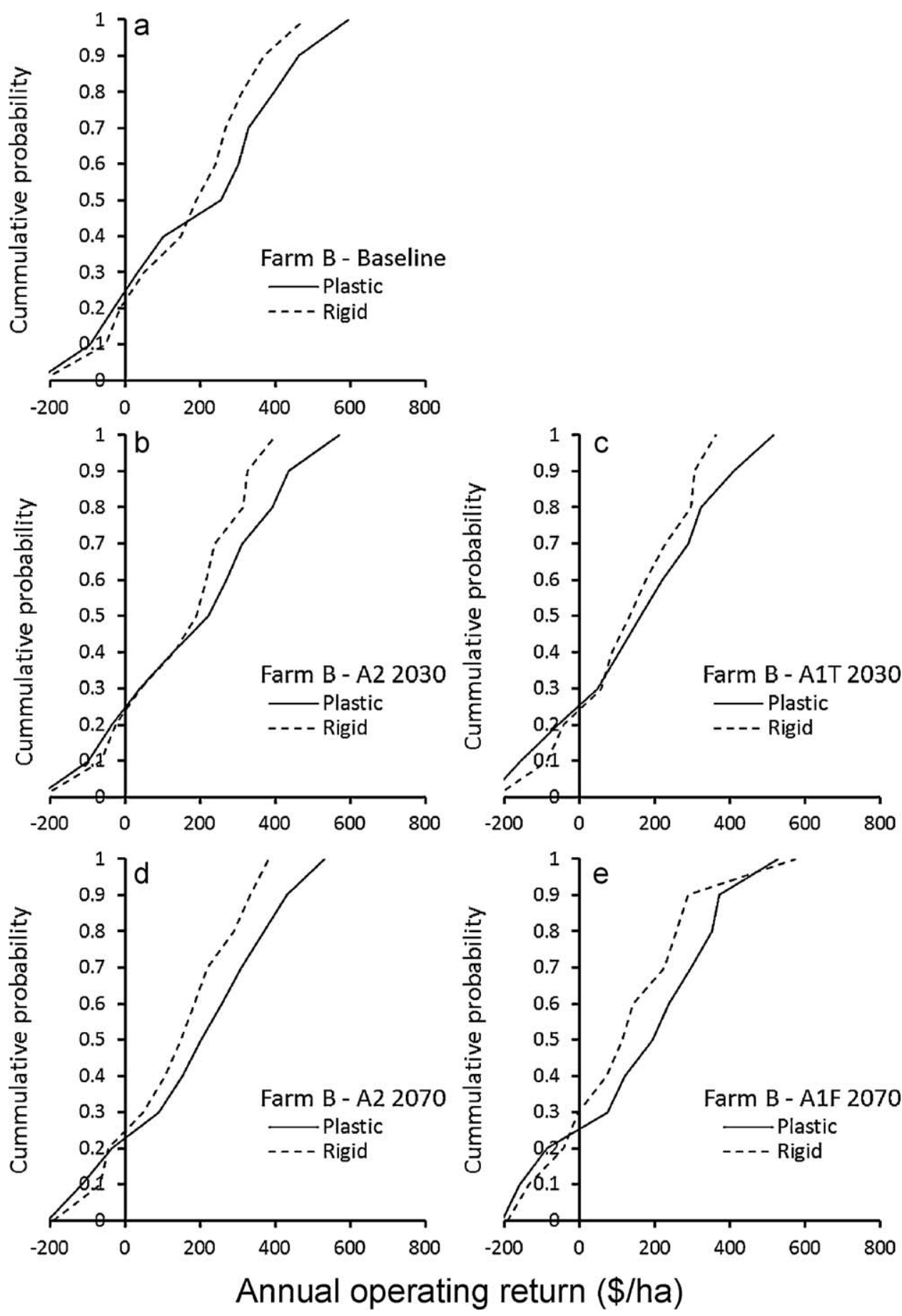

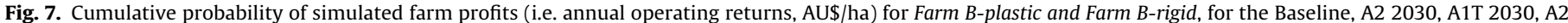
2070 and A1F 2070 climate change scenarios.

- bridge gaps between the more incremental changes in practices and tactics, with the more fundamental transformational changes and changes in business strategies - required for the design of more resilient and productive farm businesses.

We conclude that:

- plasticity in farm management can be an important source of resilience in face of uncertainty. It is likely that the value of plasticity as a strategy for adaptation to variability will depend on the nature and intensity of the change; the presence of feasible environmentally contingent alternatives; a low cost for plasticity to be implemented; and farmers' preferences.

- More integrative whole farm modelling approaches can be useful tools to identify systems characteristics that could introduce resilience into farming systems in face of uncertainty.

- We recommend that impact assessments and the identification of opportunities for adaptation to climate change should be conducted at scales most relevant to the decision maker; this is paramount in order to adequately account for the large num- 


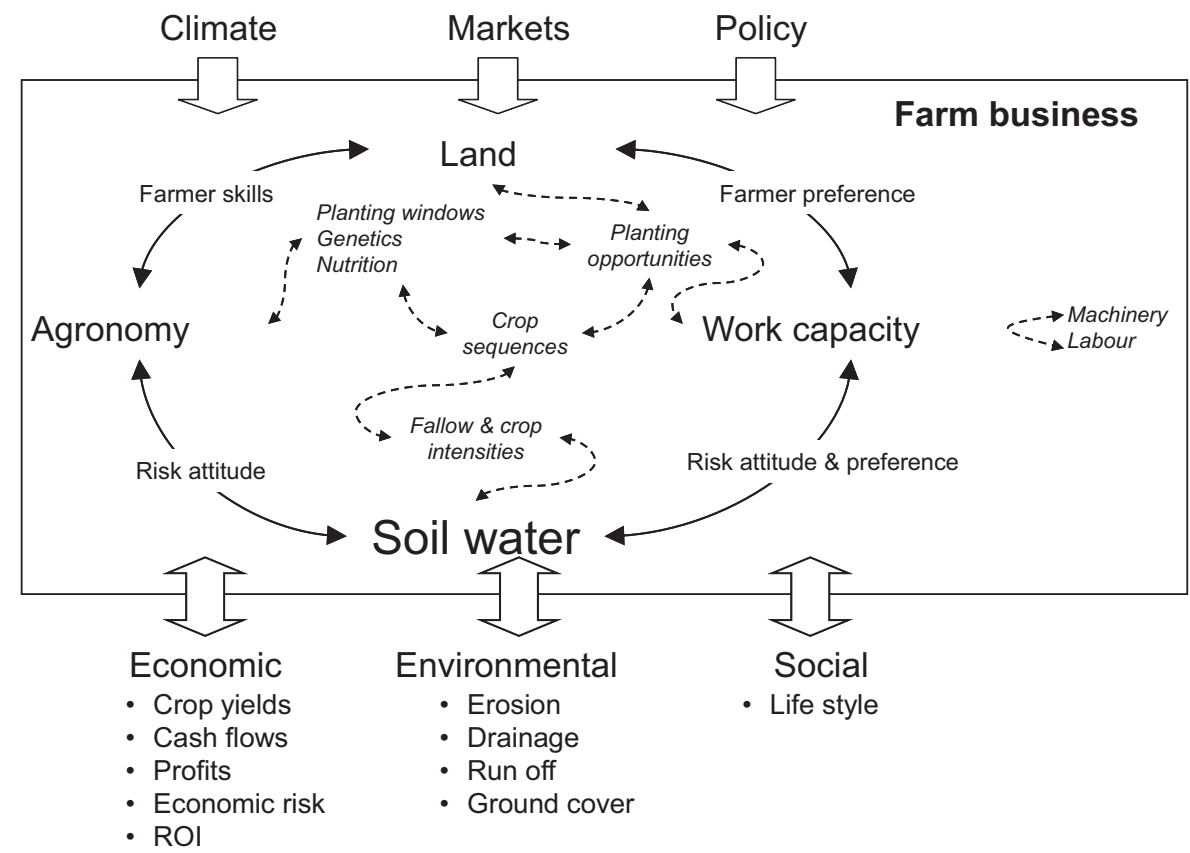

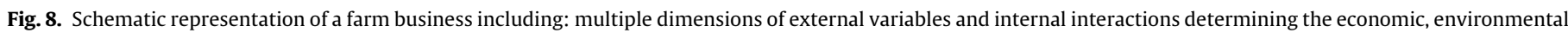
and social behaviour of the system.

ber of interacting factors We propose that in the case of adapting cropping systems to climate change the farm level should be the spatial scale of choice.

\section{Acknowledgements}

Funding was gratefully received from Agri-Science Queensland, and the Australian Department of Agriculture Fisheries and Forestry (DAFF). This work is part of the project "Developing Climate Change Resilient Cropping and Mixed Cropping/Grazing Businesses in Australia", funded by Australia's Farming Future: Climate Change Research Program (DAFF).

\section{References}

Armstrong, R.D., Millar, G., Halpin, N.V., Reid, D.J., Standleey, J., 2003. Using zero tillage, fertilisers and legume rotations to maintain productivity and soil fertility in opportunity cropping systems on a shallow Vertosol. Aust. J. Exp. Agric. 43, $141-153$.

Asseng, S., Jamieson, P.D., Kimball, B.A., Pinter, P.J., Sayred, K., Bowden, J.W., Howden, S.M., 2004. Simulated wheat growth affected by rising temperature, increased water deficit and elevated atmospheric $\mathrm{CO}_{2}$. Field Crops Res. 85, 85-102.

Challinor, A.J., Wheeler, T.R., 2008. Crop yield reduction in the tropics under climate change: processes and uncertainties. Agric. Forest Meteorol. 48, 343-356.

Challinor, A.J., Ewert, F., Arnold, S., Simelton, E., Fraser, E., 2009. Crops and climate change: progress, trends, and challenges in simulating impacts and informing adaptation. J. Exp. Bot. 60, 2775-2789.

Chataway, R.G., Doogan, V.J., Strong, W.M., 2003. A survey of dairy farmer's practices and attitudes towards some aspects of arable-land management in the Darling Downs and South Burnett regions of Queensland. Aust. J. Exp. Agric. 43, 449-457.

Crimp, S., Gartmann, A., DeVoil, P., Gaydon, D., Howden, M., Odgers, J., 2007. Adapting Australian farming systems to climate change: a participatory approach. A report to the Australian Greenhouse Office, p. 101.

DeWitt, T.J., Sih, A., Wilson, D.S., 1998. Costs and limits of phenotypic plasticity. Trends Ecol. Evol. 13, 77-81.

DeWitt, T.J., Schneider, S.M., 2004. Phenotypic Plasticity. Functional and Conceptual Approaches. Oxford Univ. Press, New York, USA.

Doole, G.J., Bathgate, A.D., Robertson, M.J., 2009. Labour scarcity restricts the potential scale of grazed perennial plants in the Western Australian wheat belt. Anim. Prod. Sci. 49, 883-893.

Garnaut, R., 2008. The Garnaut Climate Change Review. Cambridge University Press, Melbourne, Australia, 680p.

Gallopin, G.C., 2006. Linkages between vulnerability, resilience, and adaptive capacity. Global Environ. Change 16, 293-303.
Hammer, G.L., Hansen, J.W., Phillips, J.G., Mjelde, J.W., Hill, H., Love, A., Potgieter, A. 2001. Advances in application of climate prediction in agriculture. Agric. Syst. $70,515-553$.

Hansen, J.D., Liebig, M.A., Merrill, S.D., Tanaka, D.L., Krupinsky, J.M., Stott, D.E., 2007 Dynamic cropping systems: increasing adaptability amid an uncertain future. Agron. J. 99, 939-943.

Hayman, P., Whitbread, A.M., Gobbett, D.L., 2010. The impact of El Niño Southern oscillation on seasonal drought in the southern Australian grainbelt. Crop Pasture Sci. 61, 528-539.

Howden, S.M., Soussana, J.F., Tubiello, F.N., Chetri, N., Dunlop, M., Meinke, H. 2007. Adapting agriculture to climate change. Proc. Natl. Acad. Sci. U.S.A. 104, 19691-19696.

IPCC, 2007. Climate change 2007: impacts, adaptation and vulnerability. Contribution of working group II to the Fourth Assessment Report of the Intergovernmental Panel on Climate Change, Parry, M.L., Canziani, O.F., Palutikof, J.P., van der Linden, P.J., Hanson, C.E. (Eds.), Cambridge University Press, Cambridge, UK, p. 976

Keating, B.A., Carberry, P.S., Hammer, G.L., Probert, M.E., Robertson, M.J., Holzworth, D., Huth, N.I., Hargreaves, J.N.G., Meinke, H., Hochman, Z., McLean, G., Verburg, K., Snow, V., Dimes, J.P., Silburn, M., Wang, E., Brown, S., Bristow, K.L., Asseng S., Chapman, S., McCown, R.L., Freebairn, D.M., Smith, C.J., 2003. An overview of APSIM, a model designed for farming systems simulation. Eur. J. Agron. 18 267-288.

Meinke, H., Stone, R., 2005. Seasonal and inter-annual climate forecasting: The new tool for increasing preparedness to climate variability and change in agricultural planning and operations. Clim. Change 70, 221-253.

Meinke, H., Howden, M.S., Struik, P.C., Nelson, R., Rodriguez, D., Chapman, S.C., 2009. Adaptation science for agriculture and natural resource management - urgency and theoretical basis. Curr. Opin. Environ. Sust. 1, 69-76.

Nelson, D.R., Adger, W.N., Brown, K., 2007. Adaptation to environmental change: contributions of a resilience framework. Ann. Rev. Environ. Res, 32, 395419

Parry, M., Lowe, J., Hanson, C., 2009. Overshoot, adapt and recover. Nature 458 1102-1103.

Power, B., Rodriguez, D., deVoil, P., Harris, H., Payero, J., 2011. A multi-field bioeconomic model of irrigated grain-cotton farming systems. Farming Systems Design.

Rahmsdorf, S., Cazenave, A., Church, J.A., Hansen, J.E., Keeling, R.F., Parker, D.E., Somerville, R.C.J., 2007. Recent climate observations compared to projections. Science 316, 709.

Reyenga, P.J., Howden, S.M., Meinke, H., McKeon, G.M., 1999. Modelling globa change impacts on wheat cropping in south-east Queensland, Australia. Environ. Model. Software 14, 297-306.

Rosenzweig, C., Karoly, D., Vicarelli, M., Neofotis, P., Wu, Q., Casassa, G., Menzel, A., Root, T.L., Estrella, N., Seguin, B., Tryjanowski, P., Liu, C., Rawlins, S., Imeson, A., 2008. Attributing physical and biological impacts to anthropogenic climate change. Nature 453, 353-358.

Sadras, V.O., Roget, D., Krause, M., 2003. Dynamic cropping strategies for risk management in dry-land farming systems. Agric. Systems 76, 929-948.

Schwartz, B., Sharpe, K., 2006. Practical wisdom: Aristotle meets positive psychology J. Happiness Studies 7, 377-395. 
Stewart, J.I., Faught, W.A., 1984. Response farming of maize and beans at Katumani, Machakos District, Kenya: recommendations, yield expectations, and economic benefits. East Afr. Agric. Forest. J. 44, 29-56.

Stewart, J.I., Kashasha, D.A.R., 1984. Rainfall criteria to enable response farming through crop-based climate analysis. East Afr. Agric. Forest. J. 44, 58-79.

Stone, R., Hammer, G.L., Marcussen, T., 1996. Prediction of global rainfall probabilities using phases of the Southern Oscillation Index. Nature 384 252-255.
Tanaka, D.L., Krupinsky, J.M., Liebig, M.A., Merrill, S.D., Ries, R.E., Hendrickson, J.R. Johnson, H.A., Hanson, J.D., 2002. Dynamic cropping systems: an adaptable approach to crop production in the great plains. Agron. J. 94, 957-961.

Timbal, B., 2009. The continuing decline in south-east Australian rainfall: update to May 2009. Res. Lett. (CAWCR) (2), 4-11.

Tubiello, F.N., Ewert, F., 2002. Simulating the effects of elevated $\mathrm{CO}_{2}$ on crops approaches and applications for climate change. Eur. J. Agron. 18, 57-74.

Wafula, B.M., 1995. Applications of crop simulation in agricultural extension and research in Kenya. Agric. Systems 49, 399-412. 